\title{
Prevention and Prophylaxis of Youth Delinquency and Peculiarities of Appointing Punishment to Minors during a Pandemic
}

\author{
Ziyoda Yakubovna Turabaeva, \\ Independent Researcher, Tashkent State University of Law \\ ORCID ID: 0000-0001-7099-2955 \\ saarlandesziyoda@mail.ru
}

\begin{abstract}
Significant work is currently being done around the world to protect the rights of the child, pay special attention to the upbringing of minors, create the necessary conditions for them to organize their time properly, take measures to prevent them from interfering in crime and to impose penalties and impunity on juvenile offenders. In this article analyzed features of inflicting of penalties to a juvenile, peculiarities of criminal prosecution of minors, improving institutions which discharge from liability and penalty based on international experience, in particular, convicting other noncustodial penalties and other legal measures at the period of COVID-19 and further development, introducing special principles for juvenile in criminal law, the impact of punishments imposed on juvenile offenders, As well as, issues of prevention and prophylaxis of youth delinquency, measures should be taken to prevent youth delinquency, problems and solutions on this field, reforms, the forms and methods of work of government agencies involved in the prevention of delinquency among young people, causes and conditions of juvenile systemic crime, domestic legislation on prevention and prophylaxis of youth delinquency and peculiarities of appointing punishment to minors are studied. The following article expresses a number of suggestions for improving the legislation system of juvenile delinquency, features of imposing them punishment and release of them from punishment.
\end{abstract}

Keywords: juveniles, correctional system, infliction of penalty, discharge from liability and penalty.

Article Received: 10 August 2020, Revised: 25 October 2020, Accepted: 18 November 2020

\section{Introduction}

\section{Prevention and prophylaxis of delinquency among young people: problems and solutions}

During the years of independence, as a result of the rapid implementation of state youth policy in the country, many young people have gained a wide range of opportunities and recognition. Indeed, as the head of our state said, "We must bring up our children in the spirit of our highest goals, such as the prosperity of the Motherland, peace and prosperity of the people, and lead them to these goals"[1].

Despite such reforms, the forms and methods of work of government agencies involved in the prevention of delinquency among young people, first of all, do not fully meet today's requirements due to insufficient use of information and communication technologies. Government agencies often view the prevention of delinquency among young people as the sole responsibility of law enforcement agencies, and as a result do not pay enough attention to this activity.

In addition, measures to prevent and combat crime among youth are not targeted, family, community, educational institutions are not interconnected and no a comprehensive approach to this process, to identify and eliminate the causes and conditions of systemic crime and the lack of effectiveness in the development of measures does not yield the expected results.

In particular, it is almost impossible to be free from the influence of ideological 
forces in today's so-called information age, the age of electronics. The study revealed a number of problems in defining and addressing organizational and legal measures to prevent youth delinquency. Very low level of pedagogical control by parents over their children's education in higher education institutions; insufficiency of educational institutions in rural areas; the lack of a unified system of legal norms that define the level of responsibility and impose obligations on governmental and nongovernmental organizations dealing with young people (18-30 years)

All the negative conditions in society, including family unrest, shortcomings in the work of educational institutions and other areas, have a negative impact on the normal development of young people. $62.2 \%$ of delinquent youth spend their free time on the streets.

So, what measures should be taken to prevent youth delinquency? The effectiveness of crime prevention means not only knowing the laws, but also obeying the requirements of the law. E.O. Kadyrov: "Crime prevention is the establishment of a state policy to reduce, neutralize, restrict and eliminate events, incidents, processes that cause its emergence as a social phenomenon in society and this is a complex social and legal process aimed at its implementation and improvement'[2]. Article 3 of the Law of the Republic of Uzbekistan "On crime prevention", adopted on 14 May 2014 defines crime prevention. According to it, "Crime prevention is a legal, general, special, individual and victimological system of social, organizational and other measures prevention of offenses used to maintain and strengthen law and order, to identify and eliminate violations, as well as the causes and conditions of their occurrence"[3]. According to S.B. Khojakulov: "Crime prevention within the powers provided by law, effective use of sectoral services to maintain public order, ensure the safety of citizens, identify and eliminate the causes of crime and the conditions that allow them, the formation of legal awareness and culture, as well as identification of individuals who have committed a crime and committed an offense, and the correction of their morals through preventive action"[4]. In our opinion, crime prevention is a broad concept, which refers to a set of legal, social, educational processes, which include the activities of law enforcement agencies in cooperation with public organizations, citizens' self-government bodies, families and educational institutions. It can be said that the causes of juvenile delinquency include the loss of national upbringing in the family, poor attitudes of young people to education and work in the education system, lack of legal education and, in particular, the weakening influence of the neighborhood on youth life. To do this, first of all, we need to take measures to create a culture of using information technology in the minds of young people, to develop a new mechanism for preventive work with young people. At the same time, since legal education is the most important and integral part of national education, it is logical to analyze and interpret it in direct connection with national one. A leading specialist in national education, professor M. Kuronov's views on the importance of national education are noteworthy: "Every turmoil, conflict, accident, broken family, broken history in the world goes back to upbringing". It turns out to follow the path of "money first, then spirituality"[5]. Their mistake gave rise to the phrase - "Lost generation". Whole families chased after material wealth. In order to prevent such negative situations, first of all, in addition to information and analytical work, psychologists and lawyers should conduct research on the general status, scale, composition, nature and dynamics of juvenile delinquency. It is also important to take into account the factors influencing the occurrence of juvenile delinquency, to analyze the causes of certain types of crime in a particular area, especially those that have serious consequences. Most importantly, the information-analytical work on youth offenses should cover a period of at least 3-5 years. In this regard, the candidate of jurisprudence $\mathrm{J}$. 
Mukhtorov:"Effective functioning of the system for the prevention of juvenile delinquency depends on its effective provision: firstly, the proper organization of the activities of prevention services, secondly, the clear definition of their responsibilities, thirdly, cooperation with other law enforcement agencies and the public"[6]. Undoubtedly, the effective functioning of the system of crime prevention among young people depends on the proper organization of cooperation between law enforcement officers, representatives of public organizations working with them, as well as citizens.

\section{Main Part}

Prevention of delinquency among young people is the responsibility of society as a whole. A difficult adolescent is a person in need of moral correction and reeducation. Moral correction and upbringing are carried out in order to prevent him from becoming a criminal, as well as to restore normal relations with society, to form an active life position in it.

In addition to increasing the role of parents in society, the above-mentioned measures show the need educational and organizational measures aimed at raising the legal culture and legal attitudes of our youth and the formation of law-abiding behavior, as well as public control over crime prevention.

\section{Peculiarities of appointing punishment to minors during a pandemic}

In our country, which has chosen the path of building a democratic state governed by the rule of law and a strong civil society, the issue of protection of human rights and freedoms is enshrined in our national legislation. The large-scale work carried out in the field of ensuring the rule of law, raising the legal culture of the population, protection of the rights and interests of the younger generation serves this noble purpose. In this regard, one of the peculiarities of the strong social policy pursued in our country is the creation of favorable conditions for the physically, mentally and spiritually harmonious development of the younger generation. Today, along with active youth, the social situation of unorganized youth, their problems and the causes of its origin are being studied in detail by the relevant government agencies and bodies. They are provided with social, economic and spiritual support. In particular, comprehensive measures have been taken to address youth crime and its prevention, and positive results have been achieved in maintaining law and order in the country. In particular, in accordance with the Decree of the President of the Republic of Uzbekistan dated December 24, 2018 No PP-4075 "On additional measures to increase the effectiveness of public safety", the Ministry of Internal Affairs, Ministry of Defense, Central Council of the Youth Union of Uzbekistan and Citizens' Self-Government In cooperation with the Republican Council for Coordination of Activities, a joint decision was made to approve the Regulations on public patrol groups "Fidokor yoshlar" (Selfless youth). According to him, assistants of prevention inspectors will be appointed from members of the public structure "Mahalla posboni" (Neighbourhood guard) and public patrol groups "Fidokor Yoshlar"(Selfless youth). The action strategy also introduced the position of deputy head of the department head of the department for the prevention of juvenile delinquency and youth within the number of states defined in the structure of district (city) police in the MIA system [7].

At the heart of these reforms is to educate youth in a mature and harmonious way for society, the prevention of antisocial behavior in society. Prevention and fight against juvenile delinquency is one of the main directions of a strong social policy in our country. The Criminal Code of the Republic of Uzbekistan is also of special importance in this regard. Although the current Criminal Code strengthens certain provisions on the criminal liability of juveniles, it primarily provides for the protection of juvenile offenders by law through the principles of humanity, justice 
and the rule of law. There is no doubt about the importance of criminal law in protecting the next generation from criminal attacks, in preventing juvenile delinquency.

Peculiarities of criminal prosecution of minors are reflected in Section VI of the General Part of the Criminal Code of the Republic of Uzbekistan. It is known that according to Article 16 of the Criminal Code, liability for a crime is the legal consequence of the commission of a crime, which is expressed in the application of a court sentence, punishment or other legal measure.

The commission of an act that contains all the elements of a crime provided for in the Criminal Code shall be grounds for prosecution. In the Republic of Uzbekistan, a person (persons) under the age of eighteen (adulthood) is considered a child by law [8]. Therefore, in determining the liability of a juvenile for a crime in criminal law, the age of the juvenile, his specific physiological and intellectual development, the child's ability to understand the nature of his behavior, his role in society, occupation and other factors taken into account by legislator.

According to Article 17 of the Criminal Code of the Republic of Uzbekistan, sane individuals who have reached the age of sixteen before the commission of a crime are liable. However, although persons who have committed a crime before the age of eighteen shall be prosecuted in accordance with the general rules, the specifics of the liability of minors shall be taken into account in sentencing them. Also, juveniles may be prosecuted only if their actions contain the elements of a crime under Article 17 of the Criminal Code.

The system of penalties imposed on minors is different from the system of penalties imposed on adults. For example, according to Article 81 of the Criminal Code of the Republic of Uzbekistan, persons who have committed a crime under the age of eighteen are subject to fines, compulsory community service, correctional labor, restriction of liberty, and imprisonment. Penalties for adults, such as deprivation of certain rights and life imprisonment, do not apply to minors. It should be noted that according to Article 43 of the Criminal Code of the Republic of Uzbekistan, penalties in the form of restriction on service or transfer to a disciplinary unit are applied only to servicemen.

Also, no additional penalties may be imposed on minors.

The amount of penalties imposed on minors also differs from the amount of penalties imposed on adults. For example, if the fine imposed on adults is five to six hundred times the basic calculation, the fine imposed on a minor is two to twenty times the basic calculation. Also, if the penalty of imprisonment is imposed on adults for a period of one month to twenty years, for minors this penalty is applied for a period of six months to ten years [9].

The application of measures that do not adversely affect the physical and mental development of the juvenile, instead of the main types of punishment in the criminal prosecution of adults, imprisonment for a juvenile who has committed a minor or minor offense for the first time or repeatedly for a minor offense The penalty is not applied.

In each case, except for the cases provided for in Article 54 of the Criminal Code, when sentencing a juvenile, as well as his level of development, living conditions and upbringing, health, including mental development, motives for the crime, the negative impact of adults on his behavior information about him, other circumstances affecting his identity should be identified and evaluated.

Article 85 of the Criminal Code embodies these rules and individualizes the liability of minors between the ages of 13 to 16 and 16 to 18 . In particular, imprisonment applies to persons between the ages of 13 to 16 at the time of the crime:

a) for a serious crime - up to six years; 
b) for a very serious crime - up to ten years.

Imprisonment applies to persons between the ages of 16 and 18 at the time of the crime:

a) for a serious crime - up to seven years;

b) for a very serious crime - up to ten years.

It is known that the prevention and combating of juvenile delinquency is one of the most pressing issues today. In this regard, all the normative and legal acts adopted in the Republic on youth are of great importance. This is evidenced by "The Convention on the rights of the child, the laws "On state youth policy, "On education, "On guarantees of the rights of the child", the Presidential Decrees "On the strategy of actions for the further development of the Republic of Uzbekistan", "On radical improvement of the system of raising legal awareness and legal culture in society".

Despite such reforms, the forms and methods of work of government agencies engaged in crime prevention among youth do not fully meet today's requirements, primarily due to insufficient use of information and communication technologies. Government agencies often view the prevention of delinquency among youth as the sole responsibility of law enforcement agencies, and as a result do not pay enough attention to this activity. It is also important to identify and eliminate the causes and conditions of systemic delinquency, the lack of focus on measures to prevent and combat crime among youth, the inextricable link between family, community and educational institutions, and the lack of a comprehensive approach to this process, the lack of effectiveness in the development of measures does not yield the expected results. Especially in today's socalled information age, the age of electronics, it is almost impossible to be free from the influence of ideological forces. The study revealed a number of problems in defining and addressing organizational and legal measures to prevent youth delinquency. Very low level of pedagogical control by parents over their children's education in higher education institutions; insufficiency of educational institutions in rural areas; the lack of a unified system of legal norms that define the level of responsibility and impose obligations on governmental and non-governmental organizations dealing with youth (18-30 years) [10]

It is important to note that the impact of punishments imposed on juvenile offenders also remains of a more punitive rather than educational significance. This proves that the perpetrator re-offended after the conviction and thus did not achieve the intended purpose of punishment. It is expedient to consider the issue of wider protection of the rights of minors, their age, specific physiological and intellectual development, ability to understand the nature of their behavior, re-education of juvenile delinquents, wider application of the principle of humanity for them, increasing the effectiveness of penalties, criminal prosecution of juveniles and the reduction of the term of criminal liability and impunity in connection with the expiration of the sentence, to study foreign experience in this area, including the criminal law of the CIS countries.

The purpose of the liberalization of the criminal law is to enable the perpetrator to return to society by imposing other lesser punishments without isolating him from society, that is, to correct him morally, and to demonstrate measures to combat crime during judicial reform.

The study of the penal system provided for in the Criminal Code of the Republic of Uzbekistan requires further liberalization of the penitentiary system and the expansion of the range of non-segregated punishments. In the later stages of the liberalization of criminal penalties, it is expedient to expand non-segregated penalties for juveniles, ie alternatives to imprisonment, in exceptional cases, it is advisable to address the issue of juvenile 
criminal liability at the pre-trial stage and introduce modern methods of reintegration into society through social assistance, penalties, and measures to compensate for the damage caused to the system by one's own labor. In the articles and dissertations of scholars who have conducted research on this topic, many proposals have been made, such as the expansion of non-custodial punishment and other legal measures, the introduction of special principles for juveniles in criminal law [11]. According to Kolonichenkov, the imposition of fines on minors and levy of fines on the juvenile's parents or guardians violates the principle of fairness of the criminal code, as well as the purpose of the punishment is not achieved [12].

No matter how well organized the work in the colonies is, it is not a place where young people are brought up. It is also expedient to set the minimum age of the subject of the crime as fourteen years, not thirteen years. In Japan, Russia, and several other countries, children under the age of fourteen are not considered a subject of crime [13].

\section{Conclusion}

In many foreign countries, based on the requirements of international law, the priority is to reduce the punitive nature of the law and to impose penalties on minors within the limits established by law. Foreign criminal law has generally accepted criteria for sentencing juveniles, taking into account age, severity of the crime committed, and the specific characteristics of the offender [14].

The purpose of education is not legally enshrined in the current criminal code. The goal of the criminal law applicable to persons who have committed a juvenile offense should be to rehabilitate the juvenile, not to punish him for the offense he has committed. It is expedient to define in the law the effect of upbringing through re-education as the purpose of punishment, as well as to include a separate chapter on the removal of convictions. In the codes of foreign countries, there is a separate section on convictions in the section for minors. In conclusion, in the later stages of the liberalization of criminal penalties, the scope of non-custodial sentences for juveniles, ie alternatives to imprisonment, should be expanded, and in some cases the issue of juvenile criminal liability should be resolved at the pre-trial stage and returned to society through social assistance and it is practical to introduce into the penal system measures for the introduction of modern methods of compensation for damage caused by one's own labor as a criminal penalty.

Wider protection of the rights of minors, their age, specific physiological and intellectual development, the ability to understand the nature of their behavior, the re-education of young people who have committed crimes, taking into account his place in society, to apply the principle of humanity to them more widely, to increase the effectiveness of punishments, to consider the issue of criminal prosecution and reduction of terms of imprisonment and impunity in connection with the expiration of the term of imprisonment, to introduce a separate section on juvenile delinquency serves to improve the criminal law.

The court should work on the principle of individualization in sentencing a juvenile, avoid analogies in sentencing (do not impose the same punishment for the same act in the same circumstances), because the level of mental and social development of a juvenile depends on many factors - mental status, character, family environment and the situation that has arisen, the influence of the parents and their surrogates on the child, the juvenile's attitude to study and work, the views of those at school and at work on the child, the existence of life plans, and so on. Adherence to this principle ensures the achievement of the goals of re-education and rehabilitation of the juvenile, restoration of social justice and prevention of the commission of new crimes. Also, the introduction of special principles for juveniles in criminal law will help the courts to reach the right decision in the proceedings. 


\section{References}

[1] Mirziyoev Sh.M. Speech at the IV Congress of the Kamolot Youth Movement of Uzbekistan. http.www / lex.uz.

[2] Qodirov E.O. Issues of youth crime prevention. T .: 2017. - P.35

[3] http / www.lex.uz / Law of the Republic of Uzbekistan "On crime prevention"

[4] Khodjakulov S.B. Crime prevention activities of law enforcement agencies. T.: 2017. - P.5

[5] Quronov M. If you want my child to be happy ...: for parents. - Tashkent .: 2013. - P.320

[6] Abdullaeva. D. Youth delinquency and its prevention measures. http / www.huquqburch.uz.

[7] Decree of the President of the Republic of Uzbekistan "On the strategy of actions for further development of the Republic of Uzbekistan" // (Collection of Legislation of the Republic of Uzbekistan, 2017, No. 6, Article 70).

[8] Law of the Republic of Uzbekistan "On guarantees of the rights of the child". January 7, 2008, No. 139.

[9] Criminal Code of the Republic of Uzbekistan. T.: - Tashkent, Adolat $2019 \mathrm{y}$.

[10] Khodjakulov S.B. Crime prevention activities of law enforcement agencies. T.: 2017. P.5.

[11] Voloshin V.M. Some problems of differentiation of criminal punishment for minors // Russian judge. 2008. № 2. - 0.45 p.1.

[12] Kolonichenkov P.A. Peculiarities of sentencing minors under Russian criminal law // Scientific works of legal scholars of the North Caucasus region. Krasnodar, 2008. Issue. 17.-0.2 pp.
[13] Kolonichenkov P.A. Release of minors from criminal liability with the use of coercive measures of educational influence // Actual problems of combating corruption: Collection of materials of the International Scientific and Practical Conference. June 19-20, 2008. Rostov n / a, 2008. Part 2. -0.3 pp.

[14] Glushkov A.I., Pugashova GL. Problematic issues of termination of criminal prosecution against minors // Legal world. 2007. No. 12. 